\title{
Realizing Value with Data and Analytics: A Structured Literature Review on Classification Approaches of Data-Driven Innovations
}

\author{
Liza Kayser \\ University of Twente \\ 1.j.j.kayser@utwente.nl
}

\author{
Michael Fruhwirth \\ Know-Center GmbH \\ mfruhwirth@know-center.at
}

\author{
Roland M. Mueller \\ Berlin School of Economics and Law \\ roland.mueller@hwr-berlin.de
}

\begin{abstract}
Due to the growing importance of data-driven innovation, multiple streams of literature that offer varying definitions and frameworks for using data and analytics in innovation have emerged. This eventually resulted in synonymously used terminology and overlapping concepts leading to a lack of clarity and transparency. This paper investigates different aspects and variations of existing classification approaches, such as taxonomies, around data-driven innovations, and related fields. For this purpose, a systematic literature review was conducted. The resulting 30 publications were synthesized along the concepts type of study objects, type of output investigated as well as type of value dimension influenced by data and analytics. The review underlines the importance of connecting the different literature streams (e.g. data-driven or analytics business model innovation, or Analytics-as-a-Service) which emerged in recent years and hence developing a common language and knowledge basis around data-driven innovation.
\end{abstract}

\section{Introduction}

The rise of digital technologies like big data and artificial intelligence [27, 47] promote the strategic utilization of data and analytics to improve and innovate processes, products, services, and markets $[12,38,49,55,82]$ referred to as data-driven innovation (DDI) [49, 74]. In order to remain competitive, companies are urged to leverage the potentials of data and analytics.

Data has become an important source of value creation and innovation, highlighting the rising importance of DDI $[49,54,55]$. The extent to which value can be created from the use of data and analytics is becoming increasingly relevant $[13,27,36,66,68]$. As a result, the use of data and analytics is having more and more influence on the design of products, services and processes, and hence corresponding business models (BM) [82]. More and more scholars investigate the impact of data and analytics on i.a. BM innovation $[16,38,68,70]$ product and service innovation $[15,30$, $68,72]$ and process innovation [68]. More and more papers also started to thematize data and the related value dimensions within the context of business innovation $[28,35,66]$.

In recent years, various literature sources emerged that address this rising topic, while discussing i.a. data-infused [65], data-driven [68] or analytics BMs [46], big data-enabled BMs [60], data-driven products and services $[34,66,68]$. As studies around this topic increased in the last few years, scholars started to develop definitions, concepts to generate an unifying understanding of e.g. digital BMs [26] or analytics-based services [30].

Although an increasing number of studies refer to data-enhanced [29], analytics-based [30], or data-driven business models (DDBMs), products and services $[3,17,22,28]$, only a few of these studies offer a more explicit definition of these terms. Hence, terms such as "data-enhanced", "data-driven" or "analytics-based" emerged as real buzzwords in both academia and practitioner literature. Some of these terms are intended to refer to the same object or are used interchangeably, e.g. data-driven and data-enhanced [3], whereas others intentionally differentiate between data-enhanced and data-driven BMs [29], eventually leading to confusion in the community of researchers and practitioners likewise. Mertens \& Wiener [42] argue that, especially in the field of Information Systems (IS), new terms and buzzwords are introduced without carefully and systematically differentiating them from already established terms, which in turn can lead to confusion within the research community: "scientific progress is not achieved by reinventing the wheel and giving it a 
new name" [42:371]. In IS taxonomies and typologies amongst others are recognized as means to organize knowledge and classify objects $[32,48]$, referred to in this paper as classification approaches.

This paper seeks in identifying articles that provide knowledge about classification approaches developed within the context of realizing value with data and/or analytics in innovation, and asks the subsequent research question: How can innovations based on data and analytics be conceptualized along different value dimensions?

The remainder of this paper is structured as follows: Section two discusses the theoretical background about DDI, the value dimensions in business innovation as well as the usage of taxonomies in IS research. The subsequent section describes the research methodology: a systematic literature review (SLR) composed of a search and selection as well as an analysis and synthesis process. In Section 4, the results from the SLR are synthesized along the value dimensions. Finally, the paper discusses the key findings from the review and presents the implications of this research. The paper concludes with the limitations and an outlook for future work.

\section{Theoretical Background}

In this section, we present the theoretical background for this research. First, we introduce work that discusses innovations related to value. After that, we give an overview of different perspectives on how data can create value. Finally, we give an overview of existing classification approaches in the literature.

Since businesses can drive innovations by using data assets and corresponding digital technologies to improve or even innovate processes, products, services and BMs, data and/or analytics have a significant impact on business innovations and the related value dimensions [16, 38, 68, 70]. Established literature around BM innovation proposes different value-related perspectives, such as value creation, value proposition, value capturing and value network, as being one of the central parts of BMs, referred to as value dimensions [1]. Value creation is describing how activities, processes, and resources are orchestrated in an organization to develop and deliver a value proposition for a customer [33, 69]. The value proposition is defined as "the bundle of products and services that create value for a specific customer segment" [51:22] and indicates how and to what extent data and analytics can influence the value offering [44]. The value proposition focuses on how to solve customer problems and satisfy customer needs and thus create benefits through value creation [52, 80]. Value capturing is describing for what customer the value proposition is created and how it is converted into monetary benefits for the company $[11,69,73]$. The value network represents the relationships and/or interactions which a business can establish with, e.g., external partners, suppliers, end customers, and other stakeholders [1, 69]. Hence, data can be influencing every single aspect of the value dimensions, but in a different way, i.e., the type of data sources involved when considered key resources for the value creation aspect, data-driven products and services being considered as the offerings within the value proposition or monetized data the revenue stream [28, 66, 68, 81].

More and more literature streams arise what thematize the relationship or connection between data and value, whereby different study objects are being examined, e.g. value co-creation in data-driven services [66, 67], analytics-based services that deliver new added value based on data and analytics [31] or data-based value creation in information-intensive services [37], making evident that the terminology used for the particular examined study objects by scholars, for instance in the service innovation field, still varies, ranging from information-intensive services [37] over data-driven services [15] to Analytics-as-a-Service BMs [46], highlighting the importance of common knowledge and consistent nomenclature within academia and professionals [42].

Within the field of IS, there exist different approaches how study objects can be described and grouped [32, 48, 62], such as taxonomies (e.g., research on developing BM taxonomies for car-sharing BMs [57]); classification (schemes) (e.g., research on BM classifications [18]); frameworks (with research examples on a unified BM framework [1]); patterns (ranging from BM patterns in general $[23,56]$, e-health BM design patterns [71] to even sustainable BM patterns in particular [5]); archetypes (or types) [62] (e.g. archetype theory on BM types for the Internet of Things [75]); and ontologies (e.g. the BM Ontology [50] or the e3-value Ontology [25]).

Initial research revealed a selection of articles developing a variety of classification approaches around DDI and related fields, which highlights the importance of synthesizing their outcomes. Existing literature reviews on innovation perspectives of data and analytics are focusing on how value is realized with big data [27], big data capabilities [43], on how digital service innovation is enabled by big data analytics [58], on data-driven service innovation [15], or on tools and methods used to support DDI [22]. This research paper complements existing literature reviews 
by systematically identifying and reviewing existing classification approaches within the field of IS and related research streams that investigate study objects explicitly making use of data and/or analytics.

\section{Methodology}

In order to identify classification approaches of DDIs, a SLR was conducted, following the guidelines of Webster and Watson [78] and Vom Brocke et al. [7, 77]. Our structured literature review process consists of a search and selection as well as an analysis and synthesis phase that are further described in detail.

Paper search and selection process. The literature search was conducted using the three databases Scopus, IEEE Xplore, and AISeL to cover existing research from a broad range of fields, including computer science, IS and innovation and technology management. Further, filters by subject area were initially applied in Scopus to exclude contributions from irrelevant disciplines like Physics, Chemistry or Medicine.

Our search strings consist of three sets of keywords based on literature in our background section, combined by the boolean operator AND. The first and second part of the search strings is composed of keywords based on the conceptual background on BM, product/service and process innovation enabled by data and/or analytics: ("Data" OR "Analytic*") and ("Service*" OR "Product*" OR "Business Model" OR "Process" OR "Innovation"). These two sets of keywords were combined by the proximity operators PRE (for Scopus) and NEAR (for IEEE) in order to ensure that the search strings covers related search terms like data-driven business models, services, as well as synonyms (e.g. data-infused BM or analytics-based services) and other related fields. As we are interested in identifying papers that provide knowledge about classification approaches developed within the context of data and/or analytics in relation to $\mathrm{BM}$, product, service and/or process innovation, we used a broad range of keywords which include classification approaches. Hence, the third and last set of keywords was defined as "Taxonomy" OR "Classification" OR "Framework" OR "Typology" OR "Ontology" "Pattern*" OR "Type*" OR "Archetype*" based on the conceptual background on classification approaches used in IS.

Each of the three considered databases has its own functionalities and associated limitations: First, in order to harness Scopus' advanced search functionality including proximity operators, we had to split the expression ("Data" OR "Analytic*") resulting into two separate search strings (data PRE/2 (service* OR product* OR "business model" OR process OR innovation) and (analytic* PRE/2 (service* OR product* OR "business model" OR process OR innovation)); Second, IEEE Xplore uses the proximity operator NEAR which resulted in the following search string of the first two set of keywords (data OR analytic*) NEAR/2 (service* OR product* OR "business model" OR process OR innovation); Third, AISeL does not support the use of proximity operators, hence the two sets of keywords were combined by the boolean operator AND. Furthermore, the database search was conducted in the data field "(document) title" for the first two sets of keywords and in the data fields "title, abstract and keywords" in Scopus, and "abstract (only)" in IEEE and AISeL for the third set of keywords, in order to extend the search scope and hence capture relevant literature relating to classification approaches.

The database search, covering publications until June 2020, revealed 4,089 hits. The removal of duplicates and the inclusion of publications in German and English eventually resulted in a total of 3,469 publications for the subsequent screening process.

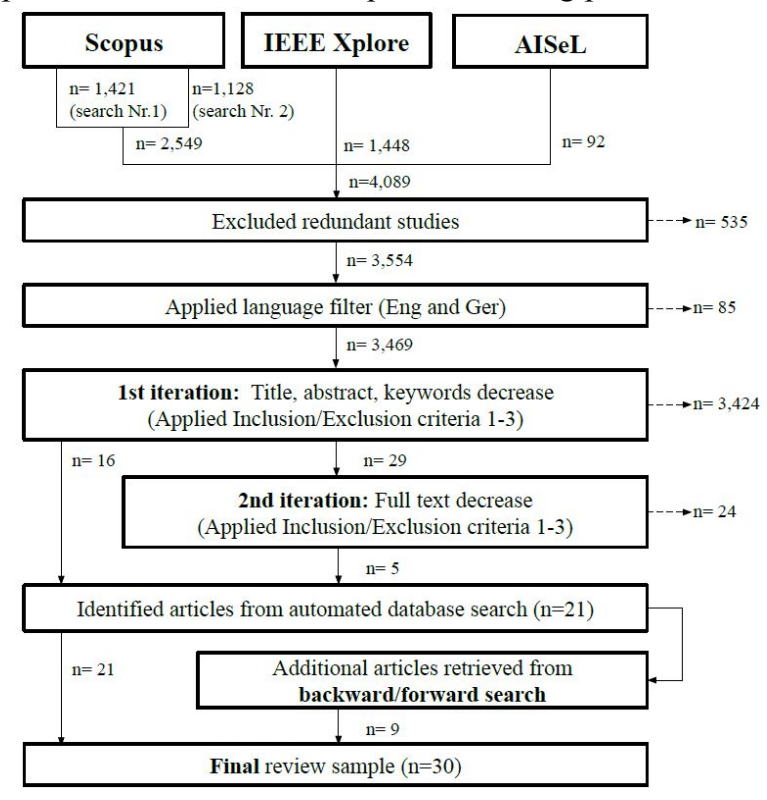

Figure 1. Search funnel

In a first iteration, two members of the author team were scanning and assessing, in parallel, the publications based on title, abstract and keywords to make sure that their content is relevant to the review scope, resulting in 45 papers. In order to be considered relevant, a particular publication had to provide a conceptualization or classification approach of BM, product/service and/or process innovations based on (big) data and/or analytics (inclusion criteria). We 
intentionally excluded papers that 1) are not related to the topic or context investigated (e.g. Process \& data mining, Data quality, Data access, Data processing, Communication networks, Web services) and 2) are only technical papers about implementations (e.g. new algorithm or techniques). The remaining 29 papers, which could not definitely be assessed based on title, abstract and/or keywords were included in a subsequent full-text screening iteration based on the above mentioned criteria, resulting in 21 hits.

The keyword search was complemented by a manual search using backward and forward citation tracking in order to collect a relatively complete census of the relevant literature $[77,78]$. Each article's reference section (from the resulting 21) was reviewed in order to trace additional prior publications relevant to the search scope (backward search). Google Scholar was used to search for relevant papers that have cited the identified articles from the second iteration (forward search). This led to four additional publications resulting from the backward and five from the forward search. In total, a final review sample of 30 papers is considered for further analysis and conceptualization. The paper selection process with its different steps and iterations is described in Figure 1.

Paper synthesis and analysis process. In order to summarize and analyze existing research, the 30 selected publications were analyzed from a concept-centric perspective [77, 78]. Within the context of this research, a concept matrix was created as the organizing framework of the literature review in the web-based collaboration platform notion in order to analyze, cluster and synthesize the identified research papers. The concept matrix is composed of the identified papers in one dimension and the identified concepts and their characteristics in the other dimension, and can also be used to identify gaps in current research $[77,78]$. The following concepts were used: 1) type of the (main) study object and corresponding definitions, 2) type of output, and 3) dimensions of the output.

The type of the (main) study object describes the object that is investigated (e.g., "data-driven business model" or "analytics-based service"). Categories of this concept were developed by an inductive approach informed by the literature on DDI (see background section). In addition, the definition of the study object provided by the authors is documented: capturing whether a paper is providing a new definition, extending existing one, following existing definitions, summarizing existing definitions or has no definition.

The type of output shows what kind of classification approach the studies generated as the main output or outcome (i.a., a taxonomy, patterns or archetypes).

The concept dimensions of the output analyzes how objects or types can be distinguished and classified. The focus lies here especially to what extent data influences the different value dimensions: 1) value creation or rather main values (activities, resources; e.g. condition monitoring), 2) the main outcome or rather value proposition and user or customer benefit (e.g. efficiency gains, improved quality, new insights, new offering), 3) value capture (financial implications and revenue streams; e.g. revenue streams from license model, subscription model), and 4) value network (e.g. value originating from sharing data across organizational units and with business/supply-chain partners; the importance of open data).

\section{Results and findings}

In this section, we first provide descriptive information on our review sample. We then present the results of our literature assessment following the review concepts introduced in section 3.2.

Descriptive results. The final review sample consists of 23 conference papers, 5 journal articles, 1 book chapter and 1 working paper, representing a variety of academic disciplines. In particular, while almost half of the studies (14) from our review nucleus were published in IS outlets, our sample also includes studies from Management (4), Social Sciences (1), Service Research \& Innovation (1), Chinese Economic and Foreign Trade studies (1) as well as from technical disciplines such as Business Informatics (incl. Information Technology) (7), Engineering (Manufacturing) (1) and Computer Science (1). Only one paper from the review nucleus was published in German, the remaining 29 were published in English.

As shown in Figure 2, the final set of publications to review was found to be published between 2011 and 2020. The graph highlights a generally increased publication number since 2016. Five different types of classifications approaches were revealed in the 30 articles from the review sample: 12 taxonomies/typologies, 11 frameworks, 7 (arche-)types, 5 patterns and 3 classification (schemes), whereby five $[14,28,46,53,59]$ of the 30 publications present various outcomes (e.g. Hartmann et al. [28] introduce a taxonomy of DDBM, a DDBM framework as well as six derived archetypes of DDBM). No ontology was represented in the review sample. The studies of the review sample examine classification approaches in different industries (e.g., web 2.0, 
fintech and traditional industries,), but with a relatively high ratio $(1 / 3)$ on the startup environment.

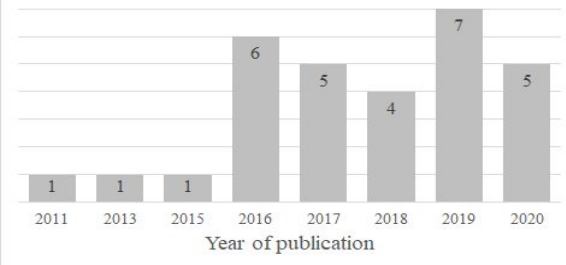

Figure 2. Distribution of years of publication

Type of study objects. Table 1 shows the distribution of the different types of (main) study objects within the considered papers, ranging from DDBM, digital services over Analytics/Data-as-a-Service (AaaS/DaaS) to more niche BM types like Urban Data BMs. 13 of the reviewed papers provide a new and/or own definition (often referring to prior research).

Table 1. Distribution of the study objects

\begin{tabular}{|c|c|c|c|}
\hline & \multicolumn{2}{|c|}{ (Main) Study objects } & \multirow{2}{*}{$\begin{array}{l}\text { Add. info: } \\
\text { Definition } \\
\text { given }\end{array}$} \\
\hline & Business Model & Product/Service & \\
\hline $\begin{array}{l}\text { Data- } \\
\text { driven }\end{array}$ & $\begin{array}{l}{[6,8,9,16,19,} \\
26,28,29,44, \\
45,61,63,84]\end{array}$ & {$[2,15]$} & $\begin{array}{l}{[16,19,26,} \\
28,29,44, \\
84]\end{array}$ \\
\hline Analytics & {$[46]$} & {$[30]$} & {$[30]$} \\
\hline (Big) data & {$[64,79]$} & & \\
\hline Data-centric & {$[14]$} & & {$[14]$} \\
\hline Digital & {$[4,26]$} & & {$[26]$} \\
\hline DaaS/AaaS & & {$[10,46]$} & {$[10]$} \\
\hline Niche & {$[40,53,83]$} & {$[37]$} & \\
\hline
\end{tabular}

From the definitions and descriptions of the different types and their characteristics of BMs, services and products based on data or analytics, it becomes apparent how strong and closely interrelated these different types are. For instance, DDBM are considered as a subtype of digital BM [4, 26, 44]. Guggenberger et al. [26] proposes a clear hierarchization: DDBM alongside digital platform BMs, data-platform BMs (as a hybrid type) and non-digital BMs) whereas AaaS and data providers are classified as subcategories of DDBMs. In contrast, Hilbig et al. [29] divide DDBMs into low data BMs, data-enhanced BMs and pure data-driven BMs. Others in turn assign AaaS to analytics BMs [10] or even consider AaaS as a type of big data BMs [64]. These discrepancies show that the field of research around
DDI is still in its infancy. The review sample did not reveal any studies with emphasis on process (innovation) as the main study object considered (hence, not included in Table 1), and if so, it is rather secondary, as part of the value proposition and/or value creation (e.g. improving internal processes).

Type of value dimension. Table 2 gives an overview of which concrete publication from the review sample is examining or discussing each of the four value dimensions. Figure 3 highlights the insights from analysing the concept of value dimension.

Table 2. Value dimension distribution

\begin{tabular}{|l|l|}
\hline $\begin{array}{l}\text { Value } \\
\text { Dimensions }\end{array}$ & Publications from the review sample \\
\hline Value creation & $\begin{array}{l}{[2,4,6,8,9,14,15,16,20,26,28,29,30,31,37,} \\
40,44,45,46,53,59,63,64,65,79,83,84]\end{array}$ \\
\hline $\begin{array}{l}\text { Value } \\
\text { proposition }\end{array}$ & $\begin{array}{l}{[2,4,6,8,9,14,15,20,26,28,29,30,31,37,44,} \\
45,46,59,63,65,79,83,84]\end{array}$ \\
\hline Value capture & {$[2,4,6,8,14,28,40,44,45,46,63: 20,79,83,84]$} \\
\hline Value network & {$[4,13,14,22,24,26,31,35,53,54,68,71]$} \\
\hline
\end{tabular}

27 out of the 30 articles thematized the value creation dimension through several aspects of DDIs. Consistent characteristics are data as a key resource or central element of the value architecture for innovation and data analytics-related key activities to derive value from the data. Single research articles also mention necessary data-driven capabilities [15], platforms [4, $44,46]$ or hard- and software needed to generate data and deliver value [40] as further characteristic elements. Engelbrecht et al. [16] summarize this as technological effort for a new BM.

Data as a key resource is further discussed from various perspectives. Data can origin from internal sources or external sources, such as freely available or customer-provided data $[8,28]$ and is generated by different entities, such as processes or physical objects [30]. Such data can contain information from different identities, like processes, products or the environment $[2,30]$. Other general types of data are business, web or streaming data [46]. From an innovation perspective, Breitfuß et al. [6] differentiate between existing and new data sources that are used. Similarly, Rizk et al. [59] differentiate between pre-existing data and data generated through the usage of the service. Another literature stream is adding data flows $[44,53]$ to their classification.

Value-adding processes [83] or key activities [28] describe how value is generated from data. This includes activities to generate or acquire data (e.g., [37] 


\begin{tabular}{|c|c|c|c|}
\hline \multicolumn{4}{|c|}{ Value Dimension of Data-Driven Innovations } \\
\hline Value Creation & Value Proposition & Value Capture & Value Network \\
\hline $\begin{array}{l}\text { - Data as a key resource } \\
\text { (external/internal data; } \\
\text { new/existing data) } \\
\text { - Value adding from data } \\
\text { through analytics related } \\
\text { activities } \\
\text { - Data-driven capabilities }\end{array}$ & $\begin{array}{l}\text { - Offering influenced by } \\
\text { degree of data and } \\
\text { analytics involvement and } \\
\text { presented as a gradual } \\
\text { decomposition } \\
\text { - Value gain (customer } \\
\text { perspective/benefit) }\end{array}$ & $\begin{array}{l}\text { - Revenue model (from } \\
\text { new to traditional) } \\
\text { - Different pricing } \\
\text { approaches within the } \\
\text { revenue models }\end{array}$ & $\begin{array}{l}\text { - Sharing data within/ } \\
\text { across organizations } \\
\text { - Open data (innovation) } \\
\text { and ecosystem } \\
\text { perspective } \\
\text { - Supporting infrastructure } \\
\text { (network relationships): } \\
\text { human and technical }\end{array}$ \\
\hline
\end{tabular}

Figure 3. Value dimension of DDI

or [40]), to prepare, process and store data (e.g., [46] or [28]), to generate insights with the help of analytics methods [28, 30] and data visualization (e.g., [46] or [29]). Further, our identified research is discussing the goals of data and analytics for value creation, e.g. Schroeder [64] denotes that data is used to inform strategic decisions or building data into products.

23 out of the 30 articles thematize the value proposition dimension in relation to data and analytics within the context of business innovation. Selected studies clearly show that the degree of how data and analytics influences the offerings can vary significantly: Breitfuss et al. [6] introduces four patterns of value proposition: 1) data-enabled improvements (e.g. internal (process) optimization) whereas the overall value proposition is not affected, processes), 2) data-enriched products and services (product/service with data/info as an add-on), 3) data-enabled services (information, knowledge or answers provided), 4) DaaS (data sold like a good) and 5) auxiliary big data services (DaaS) (non-data product or service). Hartmann et al. [28] and Brownlow et al. [8] referring to [28] also present the offering dimension as a more staggered/gradual decomposition into the presented DDBM framework: 1) data as a set of facts without meaning, 2) information/knowledge as an output of an analytics activity and 3) non-data product or service (=non-virtual offering). Bock and Wiener [4] use the term digital (market) offering for value proposition which can be described along five distinct characteristics: 1) digital products (=products in electronic form, e.g. ebook, software product and data products (selling data incl. raw data)), 2) digital services ( $=$ online exclusive, e.g. ranging from weather data, an internet search engine to online platforms), 3) human services with complimentary digital services (digitally enhanced like telemedicine services), 4) physical products with complementary digital services (e.g. manufacturing products complemented by predictive maintenance services), as well as 5) physical products with embedded digital technologies (e.g. self-learning thermostat). Hilbig et al. [29] present a comparable three-step gradation, whereby the focus is on the BM perspective and follows two dimensions "degree of data exploitation" and "degree of process digitization": ranging from 1) hardly produce any data, eventually use digital tools, to improve the value chain, over 2) e.g., a physical product gets enhanced by using digital technologies and internal data exploitation, to 3) fully digital services (like digital platforms such as Uber or Airbnb) which could even evolve to deep-learning BMs (including the self-learning aspect). Hilbig et al. [29] also focus on the dynamic perspective, in so far as a business can evolve from one stage to another. In addition, Bock and Wiener [4] emphasize the customer perspective in relation to the value proposition, called digital experience, and identified the three characteristics: 1) personalization, 2 ) engagement, and 3) community building.

14 out of the 30 articles thematize the value capture dimension. Predominantly different types of revenue models are mentioned as a characterization dimension. DDIs enable organizations of indirect monetary benefit, such as increased sales and/or customer satisfaction of their existing products and services [84]; or to generate new revenue models [6]. Thus, DDIs facilitate new types of revenue models, such as transaction or usage-based revenue models (e.g., mentioned in [2] or [44]), in addition to traditional revenue models, such as asset sale, subscription or licensing (e.g., mentioned in [28] or [40]). Within these revenue models, different pricing mechanisms are discussed (e.g., pay per user, per computing hour or per storage capacity [46]).

A bit more than one third (12) out of the 30 articles thematize the value network dimension. Certain articles interpret the dimension "value network" in a different way: 1) sharing data within a network and across organizational boundaries (external vs. internal data) $[28,79]$, while thematizing also the open data aspect of it $[15,28,64,79]$, whereas Engel and Ebel [15] are highlighting the ecosystem perspective of it (e.g., open innovation) as well as the business activities within the network (incl. customers, 
suppliers, information flows, etc.); 2) embracing the relationships [79, 83] as well as integration [4] within the network between different actors involved, incl. customers, suppliers and business partners; whereas Wiener et al. [79] is referring to it as the (underlying) supporting infrastructure and Möller et al. [44] as the organizing model. In addition, Wiener et al. [79] is distinguishing between human (i.a. analytics capabilities) and technical infrastructures (i.a. IT architectures, software systems, and algorithms) through external partners and partner networks.

\section{Discussion}

We found that existing research on classifying DDIs is mainly focusing on DDBMs. Several research papers are using the term without properly defining it. Further papers are using the term data-driven services with interchangeable main characteristics from BM literature (e.g., [2]).

Although we were searching for research on products based on data and analytics (included in the key words), we could not find any research that is conceptualizing or classifying data or analytics-based products. On the contrary, the concept of a Data Product is gaining attention in research, such as [41] as well as in practice [24]. Fruhwirth et al. [21] for instance are defining the terms data-driven business model, data-driven service and data product as interchangeable. Further, up to date, there is no academic research on understanding this concept, i.e., providing a classification scheme.

Thus a promising avenue for further research would be to conceptualize Data Products and delimitate it from already well-researched concepts, such as DDBMs or data-driven services.

Second, we found that many research articles, especially in the field of taxonomies, are studying start-ups, with sampling based on databases such as AngelList or Crunchbase. Such sampling strategies are on the one hand very transparent and thus rigor; but on the other hand, the results might be not always of high practical relevance, when excluding DDIs from established organizations, especially as established organizations not always want to develop new services and BMs, but want to extend or enhance their existing ones. Early works have studied the impact of DDIs on the BM of established organizations [65, 84].

Thus a promising avenue for further research would be to develop classification schemes of DDIs based on innovations from established firms. Further research could start with multiple case studies to understand DDs in established organizations.
Lastly, considering the value proposition dimension various nuances can be identified throughout the concerned articles: firstly, in what form does the offering come, e.g. physical product, hybrid product, data product, online exclusive, e.g., digital service and digital products, whereby no physical product is allocated. Secondly, in what form and to what extent are data and/or analytics involved (often no analytics is needed to provide a specific offering, e.g., selling (raw) data or offering DaaS), these different gradations regarding the degree of data and/or analytics involved in turn influence the aspect of value creation. However, these two aspects are still considered or examined in the studies rather separately from the added value or rather value gain generated from the customer's perspective (e.g. digital experience vs. offering [4]), highlighting the missing link between offering and value gain.

Thus further research could investigate the linkage between the offering and the value gain (i.e., the user benefit) of data or analytics based value proposition, e.g., by developing an ontology. In general, such relations are conceptualized for instance in the Value Proposition Canvas [52]. Such a research endeavor could extend existing research on DDBMs, that already link data as a resource and the value proposition [35], or data and analytics with customer benefits and needs [22], or even study the value co-creation between the customer and the service provider in data-driven services [67]. This research direction relates to the concept that real value is created through the usage of data or information $[37,39,67,76]$.

This is also closely linked to the value capture dimension. As shown in the results, existing research dealing with the value proposition mainly conceptualizing the types of revenue models and rarely the pricing mechanism. Existing research remains scarce on how to price data and analytics-based offerings. Further research could also investigate how the value gain is related to the pricing of data-driven value propositions.

\section{Conclusion, limitations, and outlook}

This paper provides the synthesis of a review sample of 30 publications on classification approaches developed within the context of data and analytics in business innovation. The synthesis informed about the solution space of DDI by analysing i.a. the value dimensions. The analysis revealed some promising avenues for further research, such as exploring the missing linkage between the offering and the value gain of data or analytics-based value proposition by 
developing e.g. an ontology. Also, research conceptualizing and delimiting data products (which is research in its infancy) from already well-researched concepts could be a promising endeavor to be considered by researchers in the field of IS.

Even though this research paper followed SLR in order to systematically search and analyze literature and holds a structured character, there are also some clear limitations to consider. First, the scope of the SLR is not completely exhaustive, even though the authors have tried to cover a broad spectrum of DDI research by preferring a database-oriented search to a journal-based search. By doing so, it has allowed the inclusion of more recent conference proceedings, which is particularly necessary when a research theme is in its infancy. In addition, the screening of the papers also involves subjective judgment. The inclusion of two reviewers from the author team for the screening as well as the specification and application of strict inclusion/exclusion criteria were intended to reduce the risk of subjective bias. Nevertheless, this does not exclude the possibility of a certain residual subjectivity.

The research focus of the SLR limited the scope to classification approaches, which means that the value dimension, in particular, could certainly not be considered exhaustively. For future research, this is an aspect that is worthwhile to investigate more closely. Moreover, this review will be used as a basis and starting point for the concrete conceptualization of DDIs, e.g., by providing a classification scheme or taxonomy of DDI based on innovations from established firms (vs. startups only).

\section{References}

[1] Al-Debei, M.M., and D. Avison, "Developing a unified framework of the business model concept", European Journal of Information Systems 19(3), 2010, pp. 359-376.

[2] Azkan, C., L. Iggena, I. Gür, F. Möller, and B. Otto, “A Taxonomy for Data-Driven Services in Manufacturing Industries", Proceedings of the 24th Pacific Asia Conference on Information Systems, (2020).

[3] Benta, C., J. Wilberg, C. Hollauer, and M. Omer, "Process model for data-driven business model generation", Design Processes | Design Organisation and Management, (2017), 347-356.

[4] Bock, M., and M. Wiener, "Towards a Taxonomy of Digital Business Models - Conceptual Dimensions and Empirical Illustrations", Proceedings of the 38th Hawaii International Conference on System Sciences, (2017).

[5] Bocken, N.M.P., S.W. Short, P. Rana, and S. Evans, "A literature and practice review to develop sustainable business model archetypes", Journal of Cleaner Production 65, 2014, pp. 42-56.
[6] Breitfuss, G., M. Fruhwirth, V. Pammer-Schindler, H. Stern, and S. Dennerlein, "The Data-Driven Business Value Matrix - A Classification Scheme for Data-Driven Business Models", Proceedings of the 32nd Bled eConference, University of Maribor Press (2019), 803-820.

[7] vom Brocke, J., A. Simons, K. Riemer, B. Niehaves, R. Plattfaut, and A. Cleven, "Standing on the Shoulders of Giants: Challenges and Recommendations of Literature Search in Information Systems Research", Communications of the Association for Information Systems 37, 2015.

[8] Brownlow, J., M. Zaki, A. Neely, and F. Urmetzer, "Data and Analytics - Data-Driven Business Models: A Blueprint for Innovation", 2015.

[9] Cheah, S., and S. Wang, "Big data-driven business model innovation by traditional industries in the Chinese economy", Journal of Chinese Economic and Foreign Trade Studies 10(3), 2017, pp. 229-251.

[10] Chen, Y., J. Kreulen, M. Campbell, and C. Abrams, "Analytics Ecosystem Transformation: A Force for Business Model Innovation”, 2011 Annual SRII Global Conference, IEEE (2011), 11-20.

[11] Chesbrough, H., "Business Model Innovation: Opportunities and Barriers", Long Range Planning 43(2-3), 2010, pp. 354-363.

[12] Curley, M., and B. Salmelin, "Data-Driven Innovation", In M. Curley and B. Salmelin, eds., Open Innovation 2.0. Springer International Publishing, Cham, 2018, 123-127. [13] Deloitte, The value of DDI (Data Driven Innovation), 2016.

[14] Dorfer, L., "Datenzentrische Geschäftsmodelle als neuer Geschäftsmodelltypus in der Electronic-Business-Forschung: Konzeptionelle Bezugspunkte, Klassifikation und Geschäftsmodellarchitektur", Schmalenbachs Zeitschrift für betriebswirtschaftliche Forschung 68(3), 2016, pp. 307-369. [15] Engel, C., and P. Ebel, "Data-Driven Service Innovation: A Systematic Literature Review and Development of a Research Agenda", Proceedings of the 27th European Conference on Information Systems, (2019).

[16] Engelbrecht, A., J. Gerlach, and T. Widjaja,

"Understanding the Anatomy of Data-Driven Business Models - Towards an Empirical Taxonomy.", Proceedings of the 24th European Conference on Information Systems, (2016).

[17] Exner, K., R. Stark, J.Y. Kim, and R. Stark, "Data-driven business model a methodology to develop smart services", 2017 International Conference on Engineering, Technology and Innovation (ICE/ITMC), IEEE (2017), 146-154.

[18] Fielt, E., "Conceptualising Business Models: Definitions, Frameworks and Classifications", Journal of Business Models 1(1), 2013, pp. 85-105.

[19] Fielt, E., K.C. Desouza, G. Gable, and P. Westerveld, "Data-Driven Business Models and Professional Services Firms: A Strategic Framework and Transitionary Pathways", In J.J. Xu, B. Zhu, X. Liu, M.J. Shaw, H. Zhang and M. Fan, eds., The Ecosystem of e-Business: Technologies, Stakeholders, and Connections. Springer International Publishing, Cham, 2019, 26-38.

[20] Förster, M., B. Bansemir, and A. Roth, "Understanding the Role of Data for Innovating Business Models: A System 
Dynamics Perspective", 14th International Conference on Wirtschaftsinformatik, (2019).

[21] Fruhwirth, M., G. Breitfuss, and V. Pammer-Schindler, "The Data Product Canvas: A Visual Collaborative Tool for Designing Data-Driven Business Models", 33rd Bled eConference Enabling Technology for a Sustainable Society, (2020), 515-528.

[22] Fruhwirth, M., C. Ropposch, and V. Pammer-Schindler, "Supporting Data-Driven Business Model Innovations - A structured Literature Review on Tools and Methods", Journal of Business Models 8(1), 2020.

[23] Gassmann, O., K. Frankenberger, and M. Csik, The business model navigator: 55 models that will revolutionise your business, Pearson, 2014.

[24] Glassberg Sands, E., "How to Build Great Data Products", Harvard Business Review, 2018.

[25] Gordijn, J., and J.M. Akkermans, "Value-based requirements engineering: exploring innovative e-commerce ideas", Requirements engineering 8, 2003, pp. 2.

[26] Guggenberger, T., F. Möller, K. Boualouch, and B. Otto, "Towards a Unifying Understanding of Digital Business Models", Proceedings of the 24th Pacific Asia Conference on Information Systems, (2020).

[27] Günther, W.A., M.H. Rezazade Mehrizi, M. Huysman, and F. Feldberg, "Debating big data: A literature review on realizing value from big data", The Journal of Strategic Information Systems 26(3), 2017, pp. 191-209.

[28] Hartmann, P.M., M. Zaki, N. Feldmann, and A. Neely, "Capturing value from big data - a taxonomy of data-driven business models used by start-up firms", International Journal of Operations \& Production Management 36(10), 2016, pp. 1382-1406.

[29] Hilbig, R., S. Hecht, and B. Etsiwah, "The Rise of Data-Driven Business Models in the Berlin Start-up Scene", Open Innovation: Bridging Theory and Practice, WORLD SCIENTIFIC (2018), 353-377.

[30] Hunke, F., C. Engel, R. Schüritz, and P. Ebel, "Understanding the Anatomy of Analytics-Based Services A Taxonomy to Conceptualize the Use of Data and Analytics in Services", Proceedings of the 27th European Conference on Information Systems, (2019).

[31] Hunke, F., S. Seebacher, R. Schüritz, and G. Satzger, "Pathways from Data to Value: Identifying Strategic Archetypes of Analytics-Based Services.", Proceedings of the 15th International Conference on Wirtschaftsinformatik, (2020).

[32] Jacob, E.K., "Classification and Categorization: A Difference that Makes a Difference", Library Trends 52(3), 2004, pp. 515-540.

[33] Johnson, M.W., C.M. Christensen, and H. Kagermann, "Reinventing Your Business Model", Harvard Business Review, 2008.

https://hbr.org/2008/12/reinventing-your-business-model [34] Kollwitz, C., M.P. Mengual, and B. Dinter, "Cross-Disciplinary Collaboration for Designing Data-Driven Products and Services", 2018 Pre-ICIS SIGDSA Symposium on Decision Analytics Connecting People, Data \& Things, 2018, pp. 1-15.

[35] Kühne, B., and T. Böhmann, "Data-driven business models - Building the bridge between data and value",
Proceedings of the 27th European Conference on Information Systems, (2020).

[36] LaValle, S., E. Lesser, R. Shockley, M.S. Hopkins, and N. Kruschwitz, "Big Data, Analytics and the Path From Insights to Value", MIT Sloan Management Review Winter issue 2011, 2011.

[37] Lim, C., K.-H. Kim, M.-J. Kim, J.-Y. Heo, K.-J. Kim, and P.P. Maglio, "From data to value: A nine-factor framework for data-based value creation in information-intensive services", International Journal of Information Management 39, 2018, pp. 121-135.

[38] Loebbecke, C., and A. Picot, "Reflections on societal and business model transformation arising from digitization and big data analytics: A research agenda", The Journal of Strategic Information Systems 24(3), 2015, pp. 149-157. [39] Lusch, R.F., and S. Nambisan, "Service Innovation: A Service-Dominant Logic Perspective", MIS Quarterly 39(1), 2015, pp. 155-175.

[40] Mcloughlin, S., A. Puvvala, G. Maccani, and B. Donnellan, "A Framework for understanding \& classifying Urban Data Business Models", Proceedings of the 52nd Hawaii International Conference on System Sciences, (2019). [41] Meierhofer, J., T. Stadelmann, and M. Cieliebak, "Data Products", In M. Braschler, T. Stadelmann and K. Stockinger, eds., Applied Data Science. Springer International Publishing, Cham, 2019, 47-61.

[42] Mertens, P., and M. Wiener, "Riding the Digitalization Wave: Toward a Sustainable Nomenclature in Wirtschaftsinformatik", Business \& Information Systems Engineering 60(4), 2018, pp. 367-372.

[43] Mikalef, P., I.O. Pappas, J. Krogstie, and M. Giannakos, "Big data analytics capabilities: a systematic literature review and research agenda", Information Systems and e-Business Management 16(3), 2018, pp. 547-578.

[44] Möller, F., M. Stachon, C. Hoffmann, H. Bauhaus, and B. Otto, "Data-driven Business Models in Logistics: A Taxonomy of Optimization and Visibility Services", Proceedings of the 53rd Hawaii International Conference on System Sciences, (2020).

[45] Müller, J., and O. Buliga, "Archetypes for data-driven business models for manufacturing companies in Industry 4.0", International Conference on Information Systems 2019 Special Interest Group on Big Data Proceedings, (2019).

[46] Naous, D., J. Schwarz, and C. Legner, "Analytics as a service: Cloud computing and the transformation of business analytics business models and ecosystems", Proceedings of the 25th European Conference on Information Systems, (2017), 487-501.

[47] Newell, S., and M. Marabelli, "Strategic opportunities (and challenges) of algorithmic decision-making: A call for action on the long-term societal effects of 'datification'", The Journal of Strategic Information Systems 24(1), 2015, pp. 3-14.

[48] Nickerson, R.C., U. Varshney, and J. Muntermann, “A method for taxonomy development and its application in information systems", European Journal of Information Systems 22(3), 2013, pp. 336-359.

[49] OECD, Data-Driven Innovation, OECD Publishing, Paris, 2015.

[50] Osterwalder, A., "The business model ontology a 
proposition in a design science approach", 2004.

[51] Osterwalder, A., and Y. Pigneur, Business Model Generation: A Handbook for Visionaries, Game Changers, and Challengers, Wiley, Hoboken, NJ, 2010.

[52] Osterwalder, A., Y. Pigneur, G. Bernarda, and A. Smith, Value proposition design: how to create products and services customers want, John Wiley \& Sons, Hoboken, 2014.

[53] Otto, B., and S. Aier, "Business Models in the Data Economy: A Case Study from the Business Partner Data Domain", Proceedings of the 11th International Conference on Wirtschaftsinformatik, (2013).

[54] Parmar, R., Driving innovation through data, IBM Institute for Business Value, 2014.

[55] Ransbotham, S., and D. Kiron, "Analytics as a source of business innovation", MIT Sloan Management Review, 2017. [56] Remane, G., A. Hanelt, J.F. Tesch, and L.M. Kolbe, "The Business Model Pattern Database - A Tool for Systematic Business Model Innovation", International Journal of Innovation Management 21(01), 2017, pp. 1750004.

[57] Remane, G., B. Hildebrandt, A. Hanelt, and L. Kolbe, "Discovering New Digital Business Model Types - a Study of Technology Startups from the Mobility Sector", PACIS, (2016).

[58] Rizk, A., B. Bergvall-Kåreborn, and A. Elragal, "Digital Service Innovation Enabled by Big Data Analytics - A Review and the Way Forward", (2017).

[59] Rizk, A., B. Bergvall-Kåreborn, and A. Elragal, "Towards a Taxonomy of Data-driven Digital Services", Proceedings of the 51st Hawaii International Conference on System Sciences, (2018), 1076-1085.

[60] Sadovskyi, O., T. Engel, R. Heininger, M. Böhm, and H. Krcmar, "Analysis of Big Data enabled Business Models using a Value Chain Perspective", (2014).

[61] Schaefer, D., J. Walker, and J. Flynn, "A Data-Driven Business Model Framework for Value Capture in Industry 4.0", Advances in Manufacturing Technology XXXI, IOS Press BV (2017), 245-250.

[62] Schilling, R.D., M.K. Haki, and S. Aier, "Introducing Archetype Theory to Information Systems Research: A Literature Review and Call for Future Research", Wirtschaftsinformatik und Angewandte Informatik, 2017. [63] Schmidt, J., P. Drews, and I. Schirmer, "Charting the Emerging Financial Services Ecosystem of Fintechs and Banks: Six Types of Data-Driven Business Models in the Fintech Sector", Proceedings of the 51st Hawaii International Conference on System Sciences, (2018).

[64] Schroeder, R., "Big data business models: Challenges and opportunities", Cogent Social Sciences 2(1), 2016. [65] Schüritz, R., and G. Satzger, "Patterns of Data-Infused Business Model Innovation", 2016 IEEE 18th Conference on Business Informatics, (2016), 133-142.

[66] Schüritz, R., S. Seebacher, and R. Dorner, "Capturing Value from Data: Revenue Models for Data-Driven Services", Proceedings of the 50th Hawaii International Conference on System Sciences, (2017), 5348-5357. [67] Schüritz, R., B. Wixom, K. Farrell, and G. Satzger, "Value Co-Creation in Data-Driven Services: Towards a Deeper Understanding of the Joint Sphere", Proceedings of the 40th ICIS, 2019.

[68] Seiberth, G., and W. Gründinger, Data-driven Business Models in Connected Cars, Mobility Services and Beyond, BVDW Research, 2018.

[69] Shafer, S.M., H.J. Smith, and J.C. Linder, "The power of business models", Business Horizons 48(3), 2005, pp.

199-207.

[70] Sorescu, A., "Data-Driven Business Model Innovation", Journal of Product Innovation Management 34(5), 2017, pp. 691-696.

[71] Sprenger, M., and T. Mettler, "On the Utility of e-health Business Model Design Patterns", (2016).

[72] van Steenbergen, M., J. van Grondelle, and L. Rieser,

"A Situational Approach to Data-Driven Service Innovation", In I. Reinhartz-Berger, J. Zdravkovic, J. Gulden and R.

Schmidt, eds., Enterprise, Business-Process and Information Systems Modeling. Springer International Publishing, Cham, 2019, 156-168.

[73] Teece, D.J., "Business Models, Business Strategy and Innovation", Long Range Planning 43(2-3), 2010, pp.

172-194.

[74] Trabucchi, D., and T. Buganza, "Data-driven innovation: switching the perspective on Big Data", European Journal of Innovation Management 22(1), 2019, pp. 23-40.

[75] Turber, S., and C. Smiela, "A Business Model Type for the Internet of Things", ECIS, (2014).

[76] Vargo, S.L., and R.F. Lusch, "Evolving to a New Dominant Logic for Marketing”, Journal of Marketing 68(1), 2004, pp. 1-17.

[77] Vom Brocke, J., A. Simons, B. Niehaves, K. Riemer, R. Plattfaut, and A. Cleven, "Reconstructing the Giant: On the Importance of Rigour in documenting the Literature Search Process", Proceedings of the Sixteenths European Conference on Information Systems (ECIS), (2009).

[78] Webster, J., and R.T. Watson, "Analyzing the past to prepare for the future: Writing a literature review", $M I S Q$ (MIS Quarterly) 26(2), 2002, pp. 13-23.

[79] Wiener, M., C. Saunders, and M. Marabelli, "Big-data business models: A critical literature review and multiperspective research framework", Journal of Information Technology 35(1), 2020, pp. 66-91. [80] Wirtz, B.W., Business model management: design instruments - success factors, Gabler, Wiesbaden, 2011. [81] Wixom, B.H., and J.W. Ross, "How to Monetize Your Data", MIT Sloan Management Review 58, 2017. https://sloanreview.mit.edu/article/how-to-monetize-your-dat a/

[82] Woerner, S.L., and B.H. Wixom, "Big Data: Extending the Business Strategy Toolbox", Journal of Information Technology 30(1), 2015, pp. 60-62.

[83] Zeleti, F.A., and A. Ojo, "The 6-Values Open Data Business Model Framework", In A. Ojo and J. Millard, eds., Government 3.0 - Next Generation Government Technology Infrastructure and Services. Springer International Publishing, Cham, 2017, 219-239.

[84] Zolnowski, A., T. Christiansen, and J. Gudat, "Business model transformation patterns of data-driven innovations", Proceedings of the 24th ECIS, Association for Information Systems (2016). 